\title{
Herpes zoster in a healthy 24-year old final year medical student one month before final examinations
}

\section{Rishi Agrawal}

\author{
Imperial College London, South Kensington, London, UK
}

Corresponding author: Dr. Rishi Agrawal, E-mail: Rishi.agrawal@doctors.org.uk

\begin{abstract}
:
Herpes zoster occurs after the varicella zoster virus reactivates and typically effects the elderly and those who are immunocompromised. Stressful and negative life events have also been associated with outbreaks of herpes zoster. However, herpes zoster that occurs in apparently healthy immunocompetent adults is relatively rare. We report a case of a healthy 24-year old male final year medical student, with no past medical or medication history, who developed herpes zoster two months before his final academic medical examinations.
\end{abstract}

Key words: Herpes zoster; Immunocompetent; Medical student; Stress; Academic examinations

\section{INTRODUCTION}

Herpes zoster (shingles) is a painful vesicular rash that occurs after the varicella zoster virus reactivates in the dorsal root ganglion of a sensory dermatome. An individual must have had a primary infection with varicella zoster (chickenpox) earlier in life in order to develop herpes zoster, which is typically seen in the elderly [1]. However, children and young adults with medical conditions that predispose towards immunosuppression may also develop herpes zoster [2], since any disease state or medication that compromises immunity has the potential to trigger latent viral reactivation. Herpes zoster that occurs in apparently healthy adults, with no history of chronic medical conditions, current illnesses or immunosuppressive medications, is rare [3]. This raises the possibility that other factors, besides the known medical causes of immunocompromise, may play a role in triggering herpes zoster.

Indeed, the stress induced by negative life events, such as bereavement, unemployment and divorce, has been associated with sporadic outbreaks of herpes zoster [4-6]. However, despite these associations with negative life events, there has yet to be a reported case of herpes zoster that is associated with the psychological stress of upcoming academic medical examinations.

\section{CASE REPORT}

A 24 year old male, with no past medical or surgical history, presented with a 1 week history of burning and extremely sensitive skin on his chest and back. Five days following the onset of his initial symptoms, a red rash appeared on his back. The patient reported no recent history of viral infection, flu-like symptoms or fever and takes no regular medications. He suffered from varicella zoster (chickenpox) at the age of 5. On social history, the patient drinks on average one unit of alcohol per week, has never smoked and has never used recreational drugs. He is a final year medical student and subjectively reports to be under a lot of stress because he is one month away from his final university medical examinations.

On examination, the patient outlined an area of painful skin that matches the distribution of the left T5 dermatome. Additionally, there are several well defined vesicles on an erythematous base in the distribution of the left dorsal T5 dermatome (Figs. la and 1b).

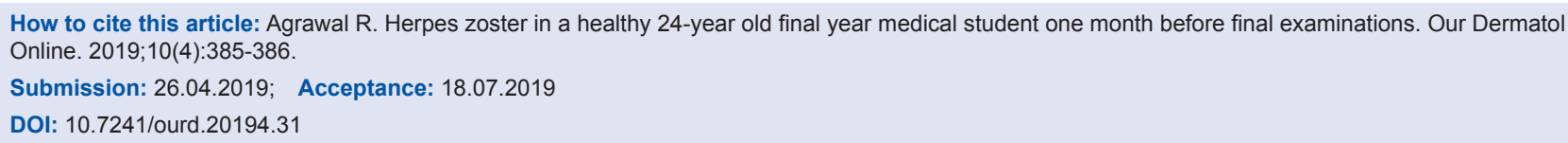




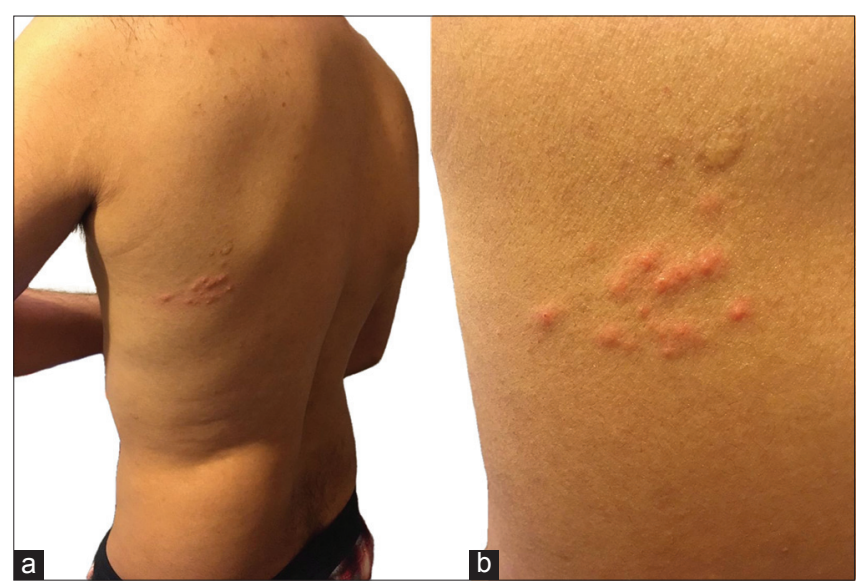

Figure 1: (a) The typical dermatomal rash of herpes zoster affecting the dorsal left T5 dermatome. (b) A higher magnification image showing many vesicles on an erythematous base.

A clinical diagnosis of herpes zoster was made in the urgent care centre and the patient was prescribed a 7-day course of acyclovir.

\section{DISCUSSION}

Herpes zoster (shingles) is most common in the elderly [1] and in the United Kingdom there has been a preventative vaccine available since 2013 for patients in their 70s. However, it can also occur in patients who are immunocompromised, either through a disease process or via medication [1]. Therefore the patient presented in this case report represents an unusual case of herpes zoster since he is a healthy 24 year old with no underlying medical conditions or any other known medical cause for immunosuppression.

This suggests that the stress induced by the patient's upcoming medical examinations may have played a role in causing a temporary state of immunocompromise, which allowed the varicella zoster virus to reactivate in the dorsal root ganglion of the left T5 dermatome. Indeed, psychological stress induced by negative life events has been associated with outbreaks of herpes zoster [4-6]. A popular mechanism involves the damaging affect of chronically high levels of endogenous glucocorticoids on the immune system. It is well recognised that high levels of cortisol can induce lymphocyte apoptosis $[7,8]$, which can subsequently reduce the immunity to viruses.

\section{CONCLUSION}

This may be one of the first case reports presenting a patient with herpes zoster that is directly associated with the stress induced by upcoming medical examinations. This case report provides further evidence for the interplay between psychological stress, immunosuppression and herpes zoster.

\section{ACKNOWLEDGEMENTS}

The author would like to thank Elizabeth Colwell BSc MRes, Imperial College London, for taking the clinical photographs.

\section{Consent}

The examination of the patient was conducted according to the Declaration of Helsinki principles.

\section{REFERENCES}

1. Yoshikawa TT, Schmader K. Herpes zoster in older adults. Clinical Infectious Diseases. 2001;32:1481-6.

2. Ferreira JC, Marques HH, Ferriani MP, Gormezano NW, Terreri MT, Pereira RM, et al. Herpes zoster infection in childhood-onset systemic lupus erythematosus patients: a large multicenter study. Lupus. 2016;25:754-9.

3. Johnson BH, Palmer L, Gatwood J, Lenhart G, Kawai K, Acosta CJ. Annual incidence rates of herpes zoster among an immunocompetent population in the United States. BMC infectious diseases. 2015;15:502.

4. Lasserre A, Blaizeau F, Gorwood P, Bloch K, Chauvin P, Liard F, et al. Herpes zoster: family history and psychological stress-casecontrol study. J Clin Virol. 2012;55:153-7.

5. Schmader K, Studenski S, MacMillan J, Grufferman S, Cohen HJ. Are stressful life events risk factors for herpes zoster? J Am Geriatr Soc. 1990;38:1188-94.

6. Schmader K, George LK, Burchett BM, Hamilton JD, Pieper CF. Race and stress in the incidence of herpes zoster in older adults. J Am Geriatr Soc. 1998;46:973-7.

7. Smith LK, Cidlowski JA. Glucocorticoid-induced apoptosis of healthy and malignant lymphocytes. Prog Brain Res. 2010;182:1-30.

8. Wang Z, Rong YP, Malone MH, Davis MC, Zhong F, Distelhorst CW. Thioredoxin-interacting protein (txnip) is a glucocorticoid-regulated primary response gene involved in mediating glucocorticoidinduced apoptosis. Oncogene. 2006;25:1903-13.

Copyright by Rishi Agrawal. This is an open-access article distributed under the terms of the Creative Commons Attribution License, which permits unrestricted use, distribution, and reproduction in any medium, provided the original author and source are credited.

Source of Support: Nil, Conflict of Interest: None declared. 